\title{
Falciform ligament instead of mesh for mini-laparoscopic hiatal hernia repair
}

\author{
Kuntay Kaplan, @ Cihan Gökler, @ Mehmet Can Aydın, @ C Cüneyt Kayaalp
}

Department of Gastroenterology Surgery, İnönü University Faculty of Medicine, Malatya, Turkey

To the Editor,

Hiatal hernia is migration of stomach partially into thoracic cavity due to the enlargement of diaphragmatic crus. Anatomically there are four groups of hiatal hernia and type 1 (gastro-esophageal junction into the thoracic cavity) is the most common. More than $90 \%$ of type 1 hiatal hernia is associated with gastro-esophageal reflux disease. ${ }^{[1]}$ In symptomatic patients, the first line treatment is long-term medical therapy. Today, the best alternative treatment to medical therapies at gastro-oesophageal reflux disease with hiatal hernia is laparoscopic Nissen fundoplication and cruroplasty. Strengthening the cruroplasty with a mesh is nowadays frequently recommended because it reduces the recurrence rates. ${ }^{[2]}$ However, there were cases in the literature in which falciform ligament were used instead of mesh for the prevention of mesh complications. ${ }^{[3,4]}$

A 62 year old male admitted with complaints of retrosternal burning, epigastric pain and vomiting for two years. Gastroesophageal reflux disease was diagnosed and a medical treatment was treated. Although the patient had been using regular anti-acid and proton pump inhibitors for the past year, his symptoms have not been declined. No disease were found in his medical history. Esophagogastroduodenoscopy indicated grade A esophagitis and hiatal hernia. The esophagogastric junction was found to be elevated $6.5 \mathrm{~cm}$ from the diaphragm level on X-ray with barium swallow, which was concordant with type 1 hiatal hernia (Fig. 1). The patient was scheduled for laparoscopic Nissen fundoplication and hiatal hernia repair. After Veress needle was inserted in the upper left quadrant, insufflation was achieved with $\mathrm{CO}_{2}$ gas as $15 \mathrm{mmHg}$ pressure. A $5 \mathrm{~mm}$ trocar was inserted $18 \mathrm{~cm}$ inferior and $4 \mathrm{~cm}$ left from the xyphoid process. A 30 degree $5 \mathrm{~mm}$ telescope was installed from this port. The other four $5 \mathrm{~mm}$ trocars were inserted under control of vision. The subxiphoid 5 $\mathrm{mm}$ trocar was placed with a liver retractor; the left lobe was elevated, and the esophagus was freed from around by dissecting both diaphragmatic cruses. The esophagogastric junction was taken to its normal position. Gastric fundus was released from greater curvature after dividing short gastric vessels. A large hiatal defect was primarily repaired from the posterior with 2/0 seperated silk sutures and it was decided additional support due to the large size of hiatal openning $(4 \mathrm{~cm})$. It was planned to use the falciform ligament flap as a support instead of mesh. The falciform ligament was released from the abdominal wall by preserving vascularization and mobilized to esophageal hiatus. It was fixed to right and left cruses one by one with 2/0 sperated silk sutures from the the posterior (Fig. 2). A 360 degrees fundoplication was performed. No drain was placed and no fascia suture was used. On first postoperative day, patient started to drink liquids. In early postoperative period, the patient's reflux complaints were completely resolved. The patient had no dysphagia and was 


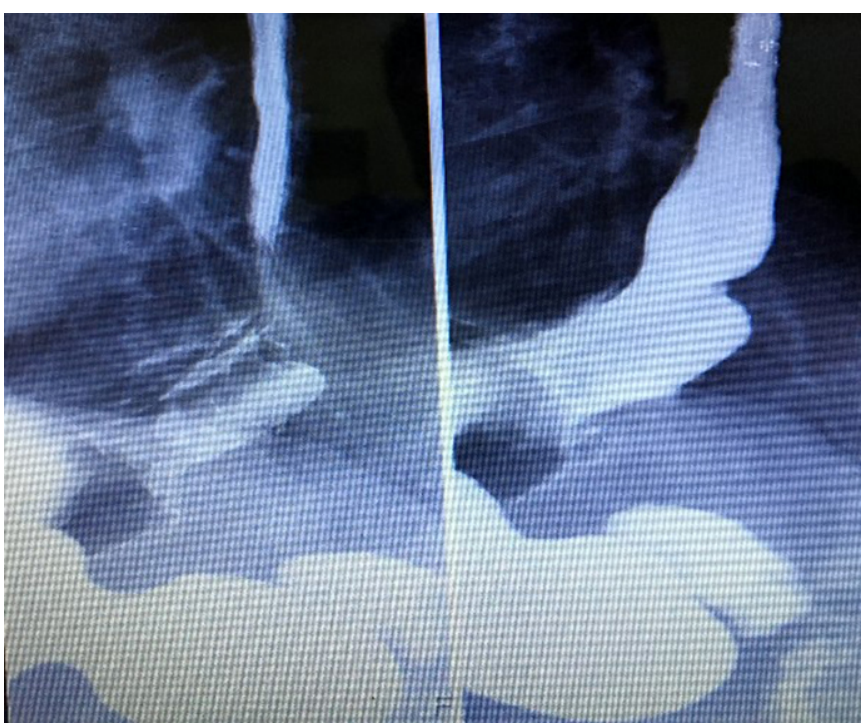

Figure 1. Hiatal defect in barium swallow.

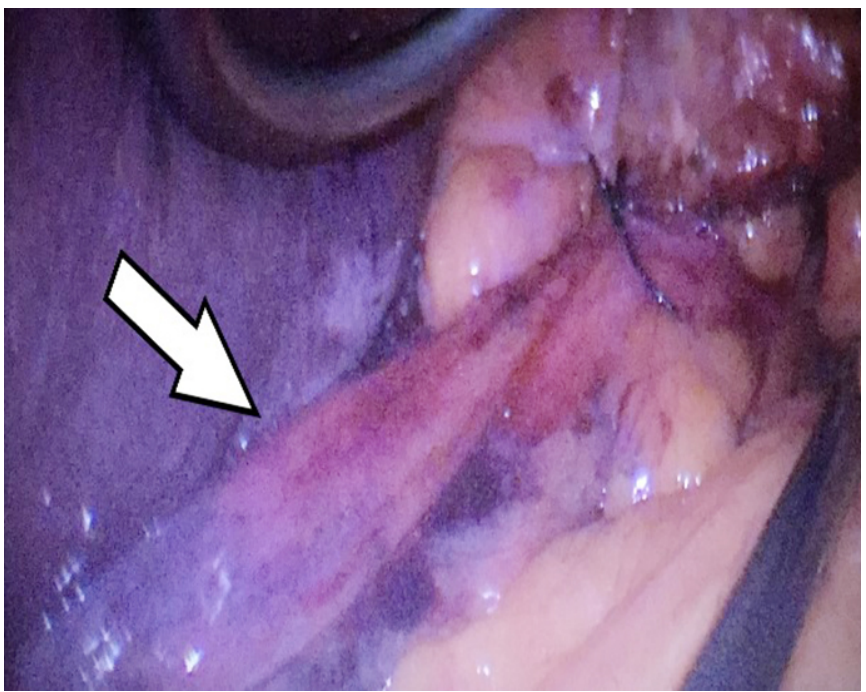

Figure 2. Fixation of falciform ligament to cruses.

discharged on the $3^{\text {rd }}$ day. The 3 day Visual Analog Scale for Pain (VAS) score average was 4.3. After two months from the operation, the patient had no reflux symptoms and no dysphagia. He had only gas bloating because of the fundoplication.
Casabella and co-workers ${ }^{[5]}$ performed the primary repair of the hiatal defect, Nissen fundoplication, and then used mesh in 15 patients. They encountered fibrous damage as well as mesh erosion extending to the esophagus in one patient. Carlson and co-workers ${ }^{[6]}$ used mesh as a support following the primary repair by open technique in 44 patients. They reported a mesh erosion extending into the esophagus in one patient. Colucco and co-workers ${ }^{[7]}$ supported the hiatal defect with mesh after primary repair. Due to the complication of the mesh, they had to perform a distal esophagus resection in one patient. Although the repair of hiatal hernia with mesh is an effective treatment, mesh itself may cause some complications, which has led to consideration of alternative methods. For this purpose the use of the falciform ligament has been considered as an option.

The first use of the falciform ligament as a support in Nissen fundoplication was first reported in a study consisting of 26 cases in 2004 by using four $10 \mathrm{~mm}$ trocars and one $5 \mathrm{~mm}$ trocar. ${ }^{[3]}$ Radiological recurrence was $15 \%$ and symptomatic recurrence was 4\%. Grossman and co-workers ${ }^{[8]}$ used a $10 \mathrm{~mm}$ camera, a $12 \mathrm{~mm}$ trocar, and three 5 $\mathrm{mm}$ trocars in their study consisting of 104 cases and they used the falciform ligament to support the primary repair of the hiatal defect, before fundoplication. They reported that this technique was well tolerated with minimal complications, and radiological recurrence rate was $\% 8.8$ in one year follow up. Laird and co-workers used a $10 \mathrm{~mm}$ port and four $5 \mathrm{~mm}$ trocars in their study of 34 cases. They used the falciform ligament as a support following the primary repair of the hiatal defect and then performed fundoplication. In six months follow up, three patients were found to have recurrence radiologically $(8.8 \%)$ and one of them was symptomatic. Park and co-workers ${ }^{[9]}$ used one $10 \mathrm{~mm}$ trocar and four $5 \mathrm{~mm}$ trocars in their study comprised of 15 cases. Likewise, they used the falciform ligament as asupport after the defect was primary repaired

Table 1. Studies which used falciform ligament in repair of hiatal hernia

\begin{tabular}{lccc} 
Study & Number of cases & $\begin{array}{c}\text { Number of } \\
\mathbf{1 2 - 1 0 - 5} \mathbf{~ m m} \text { trocar }\end{array}$ & $\begin{array}{c}\text { Recurrence rate } \\
\text { (Radyological-Symptomatic) }\end{array}$ \\
\hline Varga et al. & 26 & $0-1-4$ & $15 \%-4 \%$ \\
Grossman et al. & 104 & $1-1-3$ & $8.8 \%-0 \%$ \\
Laird et al. & 34 & $0-1-4$ & $8.8 \%-2.9 \%$ \\
Park et al. & 15 & $0-1-4$ & $0-0$ \\
Kaplan et al. & 1 & $0-0-5$ & NA/NA
\end{tabular}


and then performed a Nissen fundoplication. In the short term results, no clinical recurrence was detected in the radiological follow up. There were no adverse effects of using falciform ligament for hiatal hernia repair yet. All of the previously published studies used at least $10 \mathrm{~mm}$ in size trocars. As far as we know, there was no case of laparoscopic hiatal repair with falciform ligament with only 5 $\mathrm{mm}$ trocars (Table 1).

Although mesh repair is a more standard technique, some complications (foreign body reaction, mesh migration) may develop. Therefore, we preferred to repair with a falciform ligament to prevent these complications. We used only $5 \mathrm{~mm}$ trocars in the operation. Thus, we aimed to reduce trauma to the abdominal wall and postoperative wound complications (pain, infection, hernia). We conclude that closure of minor hiatal defects with falciform ligament can be used as an alternative technique to mesh and it may prevent complications due to mesh. We also believe that these procedures may be performed less invasively using only through $5 \mathrm{~mm}$ trocars. Using of $5 \mathrm{~mm}$ trocars is adequate for falciformopexy because there is no need for further larger trocar sites to introduce a mesh.

\section{Disclosures}

Peer-review: Externally peer-reviewed.

Conflict of Interest: None declared.

\section{References}

1. Soresi AL. Diaphragmatic Hernia: Its Unsuspected Frequency: Its Diagnosis: Technic For Radical Cure. Ann Surg 1919;69:254-70. [CrossRef]

2. Furnée E, Hazebroek E. Mesh in laparoscopic large hiatal hernia repair: a systematic review of the literature. Surg Endosc 2013;27:3998-4008. [CrossRef]

3. Varga G, Cseke L, Kalmár K, Horváth OP. Prevention of recurrence by reinforcement of hiatal closure using ligamentum teres in laparoscopic repair of large hiatal hernias. Surg Endosc 2004;18:1051-3. [CrossRef]

4. Grossman RA, Brody FJ, Schoolfield CS, Biteman B, Zeddun $S$. Laparoscopic hiatal hernia repair with falciform ligament buttress. J Gastrointest Surg 2018;22:1144-51. [CrossRef]

5. Casabella F, Sinanan M, Horgan S, Pellegrini CA. Systematic use of gastric fundoplication in laparoscopic repair of paraesophageal hernias. Am J Surg 1996;171:485-9. [CrossRef]

6. Carlson MA, Condon RE, Ludwig KA, Schulte WJ. Management of intrathoracic stomach with polypropylene mesh prosthesis reinforced transabdominal hiatus hernia repair. $\mathrm{J}$ Am Coll Surg 1998;187:227-30. [CrossRef]

7. Coluccio G, Ponzio S, Ambu V, Tramontano R, Cuomo G. Dislocation into the cardial lumen of a PTFE prosthesis used in the treatment of voluminous hiatal sliding hernia, A case report. [Article in Italian] Minerva Chir 2000;55:341-5.

8. Laird R, Brody F, Harr JN, Richards NG, Zeddun S. Laparoscopic Repair of Paraesophageal Hernias with a Falciform Ligament Buttress. J Gastrointest Surg 2015;19:1223-8.

9. Park $A E$, Hoogerboord CM, Sutton E. Use of the falciform ligament flap for closure of the esophageal hiatus in giant paraesophageal hernia. J Gastrointest Surg 2012;16:1417-21. 